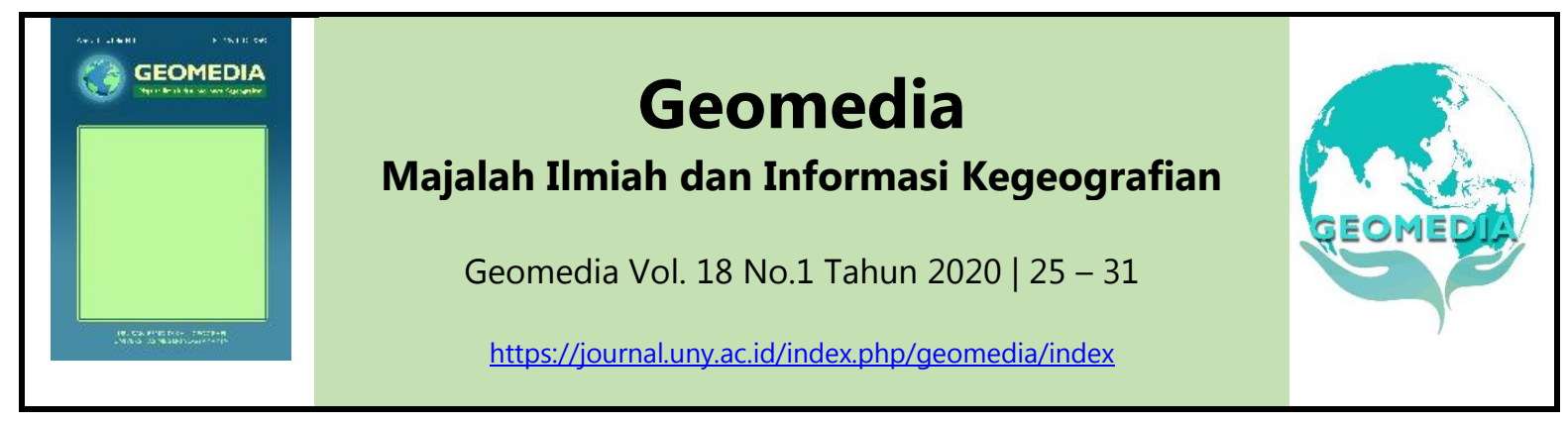

\title{
Transformasi Indeks Vegetasi Citra Sentinel 2 A untuk pemetaan produktivitas lahan sawah Kabupaten Magelang
}

\author{
Alfiatun Nur Khasanaha, ${ }^{a,}{ }^{\star}$, Dian Octaviani ${ }^{\text {b, }}$, \\ a,b Penginderaan Jauh dan Sistem Informasi Geografi Departemen Teknologi Kebumian Sekolah Vokasi Universitas \\ Gadjah Mada \\ ${ }^{1}$ alfiatunnur.k@ugm.ac.id*; ${ }^{2}$ dianoctaviani.23@gmail.com
}

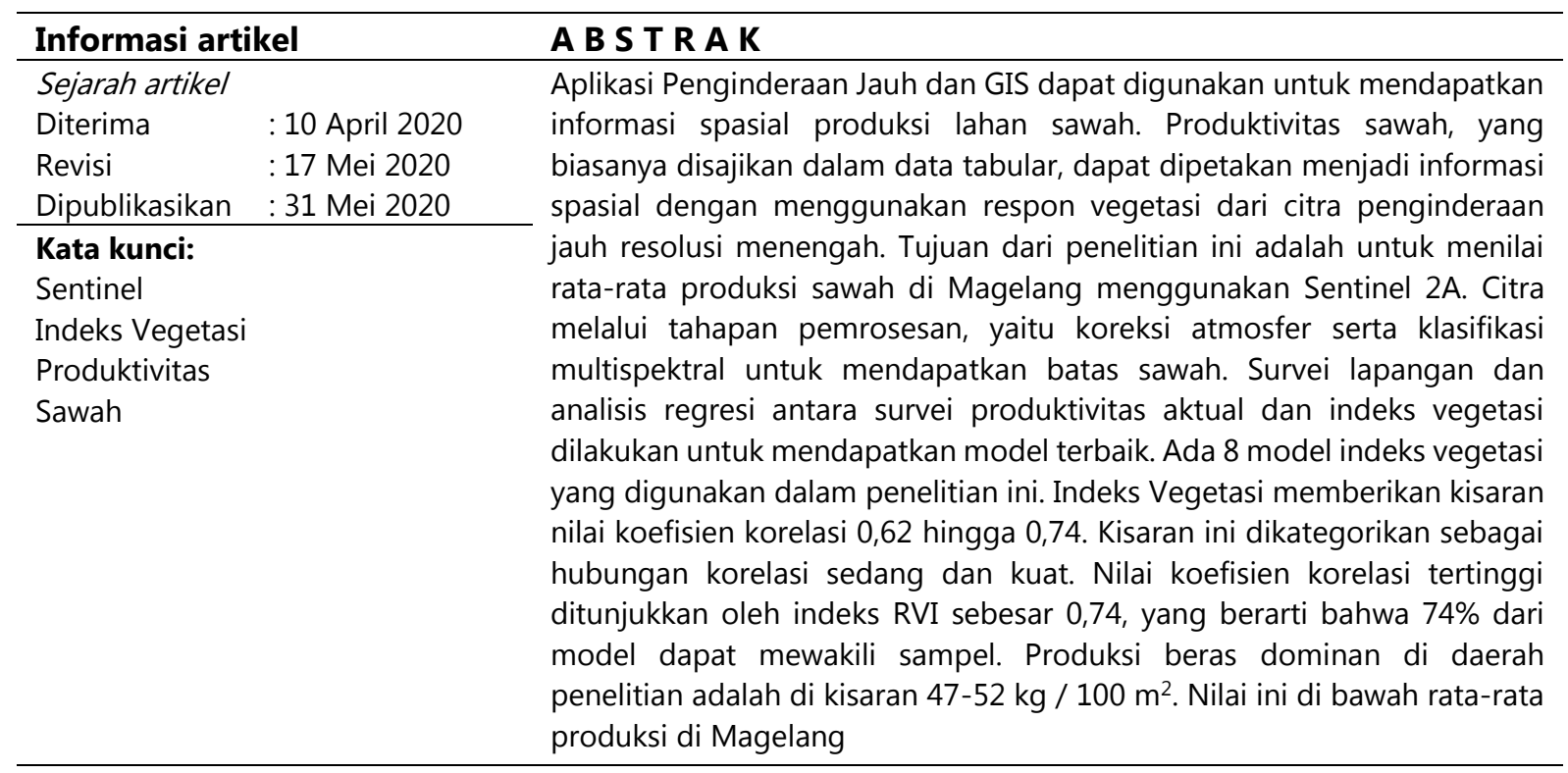

\section{Keywords:}

Sentinel

Vegetation Indices

Productivity

Field

\section{A B S T R A C T}

The application of Remote Sensing and GIS can be used to obtain spatial information of rice production. Field Productivity, which usually presented in tabular data, can be mapped into spatial information within the applied medium resolution of satellite imagery based on spectral vegetation response. The purpose of this study is to assess the average rice production in Magelang using Sentinel 2A Images. This images processed in the form of atmospheric correction, also using maximum likelihood classification to obtain paddy field's border. Field surveys and regression analysis between the actual productivity surveys and vegetation indexes carried out to obtain the best model. There are 8 vegetation index models used in this study. The Vegetation index gives a range of correlation coefficient values of 0.62 to 0.74 . This range categorized as a moderate and robust correlation relationship. The highest correlation coefficient value is shown by the RVI index of 0.74 , which means that $74 \%$ of the model can represent the sample. The RVI index shows the best model in this research. The dominant rice production in the study area is in the range of $47-52 \mathrm{~kg} / 100 \mathrm{~m} 2$. This value is below the average production in Magelang (underestimation) 


\section{Pendahuluan}

Kunci sukses capaian Sustainable Development Goals (SDGs) di Indonesia, salah satunya, terletak pada indikator kinerja sektor pertanian (Haryono et al, 2014). Indikator tersebut menilai kerawanan pangan dengan mempertimbangkan wilayah geografis baik daerah dengan potensi produksi pangan yang tinggi maupun variasi pasokan pangan antar daerah (BPS, 2014). Seiring dengan berkembangnya teknologi dalam bidang penginderaan jauh dan Sistem Informasi Geografi, informasi produksi padi yang disajikan dalam bentuk data tabular, dapat dikembangkan menjadi informasi spasial dengan data survey maupun peta. Hal ini akan memudahkan pengguna dalam memperoleh informasi secara cepat dan akurat (Murti dan Ratna, 2018). Badan Pusat Statistik bekerjasama dengan beberapa instansi lain mengembangkan metode perhitungan produksi lahan pertanian dengan Kerangka Sampel Area (KSA) dan memanfaatkan citra resolusi tinggi dan verifikasi data lapangan (BPS, 2015).

Selain itu, terdapat penelitian mengenai penilaian produktifitas tanaman menggunakan indeks vegetasi pada citra resolusi menengah telah dilakukan oleh Aswin dan Murti (2016); Said, Subiyanto dan Yuwono, (2015); Murti dan Ratna (2018). Berbagai indeks vegetasi juga digunakan untuk mengekstraksi data nilai faktor $C$ dalam erosi. Sulistyo, Gunawan, Hartono dan Danoedoro (2011) menunjukkan bahwa korelasi antara indeks vegetasi dan kondisi fisik tanaman memberikan hasil yang berbeda beda di setiap wilayah. Indeks vegetasi yang kompleks dan mempertimbangkan pengurangan pantulan dari obyek lain selain vegetasi memiliki tingkat korelasi yang tinggi dengan kondisi fisik tanaman.

Berdasarkan latar belakang tersebut, dilakukan penelitian dengan tujuan menganalisa model indeks vegetasi terbaik untuk pemetaan produktivitas lahan pertanian di Kabupaten Magelang. Pemetaan ini juga berguna untuk mengetahui sebaran spasial rata rata produksi lahan sawah di Kabupaten Magelang sebagai upaya untuk mengetahui ketahanan pangan di daerah tersebut.

\section{Metode \\ Lokasi Penelitian}

Lokasi penelitian berada di Kabupaten Magelang, Provinsi Jawa Tengah (Gambar 1) dengan luas 108,6 ha . Kabupaten ini terletak diantara $110^{\circ} 26^{\prime} 51^{\prime \prime}$ dan $110^{\circ} 26^{\prime} 58^{\prime \prime}$ BT sampai dengan antara $7^{\circ} 19^{\prime} 13^{\prime \prime}$ dan $7^{\circ} 42^{\prime} 16^{\prime \prime}$ LS. Secara fisiografis, Kabupaten Magelang terletak pada dataran alluvial dan dikelilingi gunung api sehingga kondisi tanah di wilayah tersebut cocok untuk pertanian. Sektor pertanian memberikan kontribusi yang besar dalam PDRB Kabupaten Magelang.. Luas panen padi sawah di Kabupaten Magelang adalah $59.084 \mathrm{Ha}$ dengan produksi padi 364.198 ton dan memiliki produktivitas 61.64 $\mathrm{Kw} / \mathrm{Ha}$ (BPS, 2015).

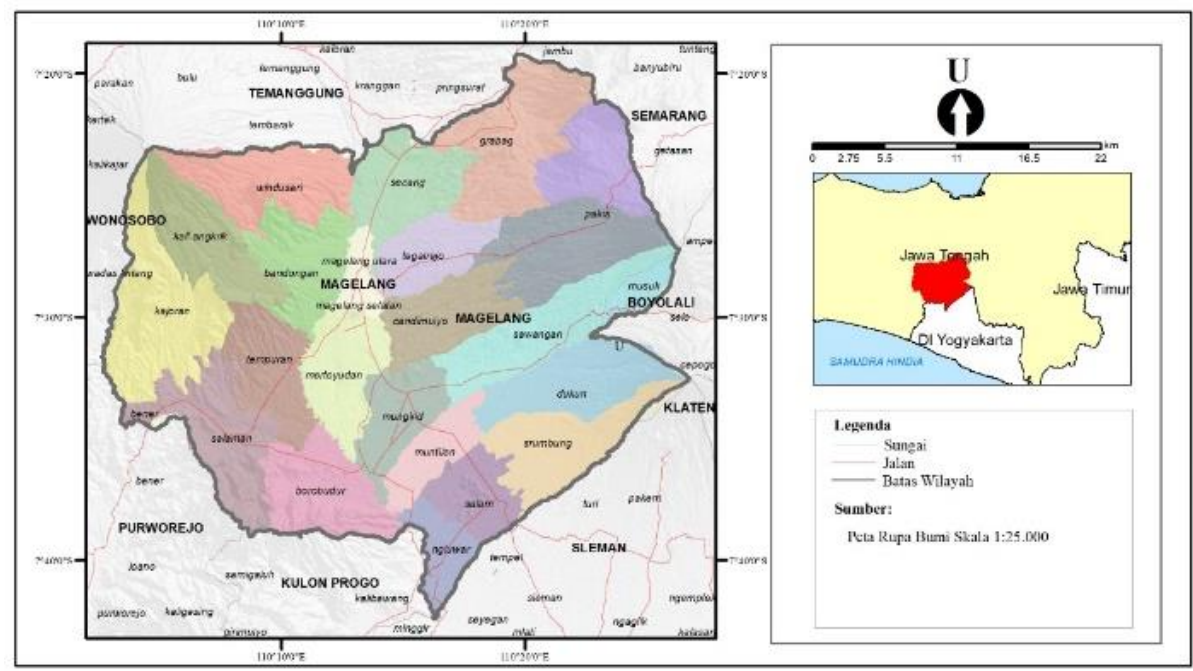

Gambar 1. Peta Lokasi Penelitian 


\section{Data dan Sumber Data}

Penelitian ini menggunakan data utama berupa 2 scene Citra Sentinel Multi-Spectral Instrumen (MSI) 2A Level 1C 2 perekaman 14 Mei 2018. Citra ini telah terkoreksi geometrik dan radiometrik dan dapat didownload secara gratis melalui https://earthexplorer.usgs.gov/. Selain itu digunakan pula peta dasar yang dapat diakses melalui http://tanahair.indonesia.go.id/portalweb. Website tersebut menyediakan data dasar berupa batas administrasi, hidrografi maupun sarana trasnportasi Indonesia berbagai skala. Pengolahan citra serta pemrosesan indeks vegetasi menggunakan Software Sentinel Aplication Platform (SNAP) versi 6.8. Digunakan pula software Quantum GIS untuk visualisasi peta.

\section{Tahapan Penelitian}

Tahapan penelitian dimulai dari prapengolahan citra serta ekstraksi data lahan baku sawah, pengolahan indeks vegetasi, penentuan sampel dan survei lapangan dan terakhir adalah analisa hubungan produktivitas lahan sawah dengan indeks vegetasi. Pra -pemrosesan citra dimulai dengan melakukan koreksi atmosferik pada citra Sentinel 2A untuk mengubah nilai radians menjadi nilai pantulan. Proses ini berfungsi untuk untuk meningkatkan hasil akurasi model indeks vegetasi. Proses Koreksi dilakukan dengan menggunakan tools Semi Automatic Detection pada software Quantum GIS. Setelah dilakukan proses koreksi, langkah selanjutnya adalah melakukan mosaic dua scene citra Sentinel untuk mendapatkan kenampakan menyeluruh di daerah kajian.

\section{Klasifikasi Penutup Lahan dan Ekstrasi Penggunaan Lahan Sawah}

Klasifikasi penutup lahan dilakukan untuk mendapatkan batas area persawahan. Klasifikasi dilakukan secara otomatis menggunakan metode terselia (supervised classification) dengan teknik maximum likelihood. Wilayah kajian dibagi menjadi 8 kelas penutup lahan yaitu vegetasi, lahan terbangun, lahan terbuka, awan dan bayangan awan, serta tubuh air. Komposit yang digunakan untuk identifikasi penggunaan lahan adalah komposit 832 pada citra Sentinel. Komposit ini dipilih untuk menonjolkan efek vegetasi. Masing masing kelas diwakili oleh sampel ROI (Region of Interest) sebagai masukan dalam proses klasifikasi.Verifikasi data lapangan serta revisi batas lahan sawah perlu dilakukan untuk mendapatkan batas lahan sawah yang sesuai dengan kondisi lapangan. Verifikasi batas juga dilakukan menggunakan data kemiringan lereng dan ketinggian tempat.

Survey lapangan dilakukan dengan tujuan untuk mendapatkan nilai produksi lahan sawah pada sampel terpilih serta untuk melakukan cek hasil klasifikasi lahan sawah. Sampel ditentukan menggunakan metode Stratified Random Sampling berdasarkan hasil pengkelasan nilai indeks vegetasi

\section{Pemrosesan Indeks vegetasi}

Indeks vegetasi merupakan kombinasi matematis saluran atau band yang menunjukan kondisi vegetasi hijau (Lillesand and Kiefer, 2004). Indeks ini dikembangkan 40 tahun yang lalu dengan berdasarkan pada karakteristik pantulan spektral dari vegetasi yang dipengaruhi oleh kandungan pigmen daun, material organik, air, dan karakteristik struktural daun (Jensen, 2000). Indeks tersebut mempunyai berbagai macam variasi algoritma. Beberapa macam algoritma yang digunakan dalam penelitian ini dapat dilihat pada Tabel 1.

Tabel 1. Rumus Indeks Vegetasi

\begin{tabular}{|c|c|}
\hline Indeks & Rumus \\
\hline $\begin{array}{l}\text { Normalized Difference } \\
\text { Vegetation Index (NDVI) }\end{array}$ & $\frac{N I R-R E D}{\frac{N I R+R E D}{N}}$ \\
\hline $\begin{array}{l}\text { Ratio Vegetation Index } \\
\text { (RVI) } \\
\text { Soil Adjusted Vegetation } \\
\text { (SAVI) }\end{array}$ & $\begin{array}{l}\frac{N I R}{R E D} \\
\frac{N I R-R E D}{N I R+R E D+L} \\
\star(1+\mathrm{L})\end{array}$ \\
\hline $\begin{array}{l}\text { Difference Vegetation Index } \\
\text { (DVI) }\end{array}$ & 2,4 * (NIR-RED) \\
\hline Vegetation Index Faster (VIF) & $\frac{N I R}{N I R+R E D}$ \\
\hline $\begin{array}{l}\text { Enhance Vegetation Index } \\
(\mathrm{EVI})\end{array}$ & $\begin{array}{l}2,5 \text { * } \\
\frac{N I R-R E D}{1+N I R+6 R E D+7,5 B}\end{array}$ \\
\hline
\end{tabular}




\begin{tabular}{ll}
\hline Indeks & Rumus \\
\hline $\begin{array}{l}\text { Atmospherically Resistance } \\
\text { Vegetation Index (ARVI) }\end{array}$ & $\frac{N I R-B}{N I R+B}$ \\
$\begin{array}{l}\text { Transformed Vegetation } \\
\text { Index (TVI) }\end{array}$ & $\sqrt{\frac{N I R-R E D}{N I R+R E D}}+\mathrm{L}$ \\
\hline
\end{tabular}

$\begin{aligned} & \text { Keterangan : } \\ & \text { NIR }=\text { Saluran Inframerah Dekat } \\ & \text { RED }=\text { Saluran Merah } \\ & B=\text { Saluran Biru } \\ & L=0.5 \text { (nilai konstanta) }\end{aligned}$

\section{Analisa hubungan produktivitas lahan dan indeks vegetasi}

Pengaruh antara variabel terikat (y) berupa produktifitas padi aktual dengan variabel bebas $(x)$ berupa nilai indeks vegetasi diprediksi menggunakan metode regresi linier. Persamaan dari analisis regresi adalah sebagai berikut :

$$
y=a x+b
$$

dimana, nilai a dan b adalah konstanta.

\section{Hasil dan pembahasan}

Hasil klasifikasi penutup lahan dapat dilihat pada Gambar 2. Indeks keterpisahan (Separability index) antar kelas berkisar antara 1,7 hingga 1,9. Artinya, masing masing kelas telah memiliki perbedaan respon spektral yang tegas. Indeks separabilitas paling kecil ditunjukkan oleh penutup lahan berupa vegetasi kerapatan rendah dan vegetasi kerapatan sedang serta tubuh air. Lahan sawah dengan berbagai kondisi akan memberikan respon spektral yang beragam pada citra. Pada kondisi penggenangan, respon air akan lebih dominan dibandingkan dengan tanaman. Kondisi ini akan berubah seiring dengan perkembangan tanaman padi.

Penggunaan lahan yang dominan di daerah kajian adalah vegetasi. Setelah mengalami revisi batas, survei lapangan dan analisa kemiringan lahan didapat luas lahan sawah total 28.566 ha. Lahan tersebut tersebar merata di seluruh wilayah Kabupaten Magelang. Lahan sawah paling luas berada di Kecamatan Secang sebesar 2.233 Ha. Grafik estimasi luas lahan sawah di Kabupaten
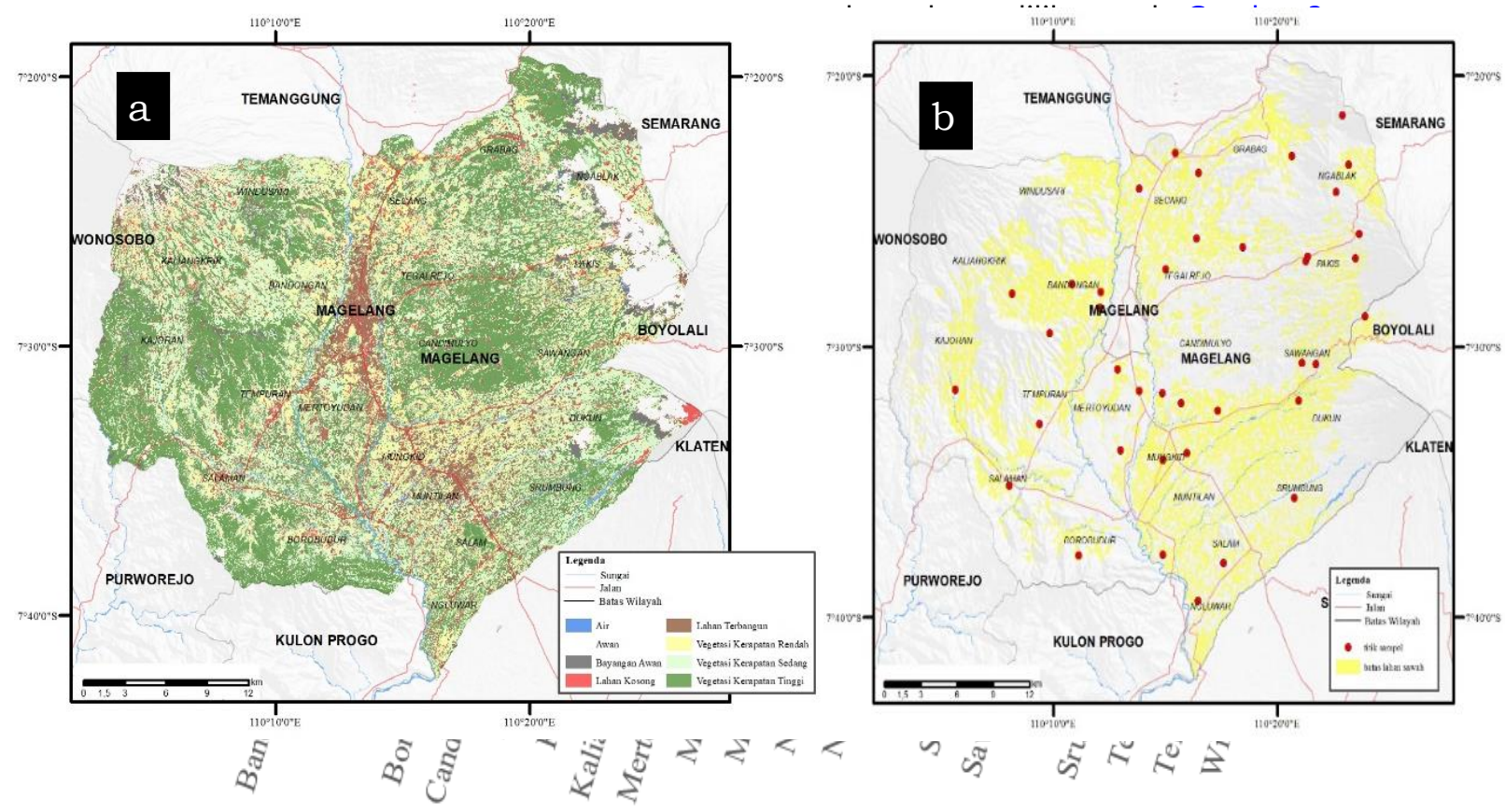

Kecamatan

Gambar 2. Hasil Klasifikasi Tutupan Lahan di Kabupaten Magelang

\section{Hasil transformasi indeks vegetasi}

Hasil transformasi indeks vegetasi memberikan nilai statistik yang beragam (Tabel 2). Variasi data dari indeks vegetasi dapat dilihat berdasarkan nilai standar deviasi. Standard deviasi terbesar adalah transformasi RVI sebesar 1,78. Transformasi ini memiliki interval nilai yang lebih besar yaitu antara 0,4 sampai 13,26 . Transformasi 
ini menggunakan rumus yang paling sederhana dibandingkan dengan transformasi lainnya.

Hasil survey lapangan produktivitas padi dibandingkan dengan nilai indeks pada lokasi sampel menggunakan metode regresi linier. Data outlier dihilangkan untuk mendapatkan niai koefisien korelasi yang lebih baik. Contoh grafik korelasi indeks RVI dapat dilihat pada gambar 4. Indeks vegetasi memberikan rentang nilai koefisien korelasi 0.62 hingga 0.74 . Rentang ini dikatagorikan sebagai hubungan korelasi sedang dan kuat. Nilai koefisien korelasi paling tinggi ditunjukkan oleh Indeks RVI sebesar 0.74 artinya, 74 \% sampel dapat direpresentasikan oleh model.

Koefisien korelasi yang dihasilkan dari pengukuran hubungan antara produktivitas dan indeks vegetasi memiliki nilai yang berbeda beda antar wilayah. Aswin dan Murti (2016) menunjukkan koefisien korelasi ARVI memiliki indeks yang lebih tinggi dibanding dengan indeks lainnya pada studi. Nilai indeks vegetasi dan hasil analisa statistik berupa regresi maupun korelasi peka terhadap jenis data dan kualitas citra yang digunakan serta waktu perekaman. Waktu perekaman mengindikasikan tahapan pertumbuhan padi yang secara tidak langsung akan berpengaruh terhadap nilai pantualan maupun serapan di gelombang tampak dan inframerah.

Tabel 2. Rumus Indeks Vegetasi

\begin{tabular}{llll}
\hline Indeks & Rumus Korelasi & \multicolumn{1}{c}{$\mathbf{r}^{2}$} & \multicolumn{1}{c}{$\mathbf{r}$} \\
\hline TVI & $y=59,537 x-19,863$ & 0,459 & 0,677 \\
EVI & $y=91,516 x+31,415$ & 0,518 & 0,72 \\
VIF & $y=100,97 x-25$ & 0,518 & 0,72 \\
DVI & $y=47,287 x+31,686$ & 0,439 & 0,663 \\
RVI & $y=5,6635 x+29,552$ & 0,554 & 0,744 \\
ARVI & $y=69,334 x+6,2762$ & 0,48 & 0,693 \\
SAVI & $y=71,422 x+29,318$ & 0,475 & 0,689 \\
NDVI & $y=50,484 x+25,484$ & 0,518 & 0,72 \\
\hline
\end{tabular}

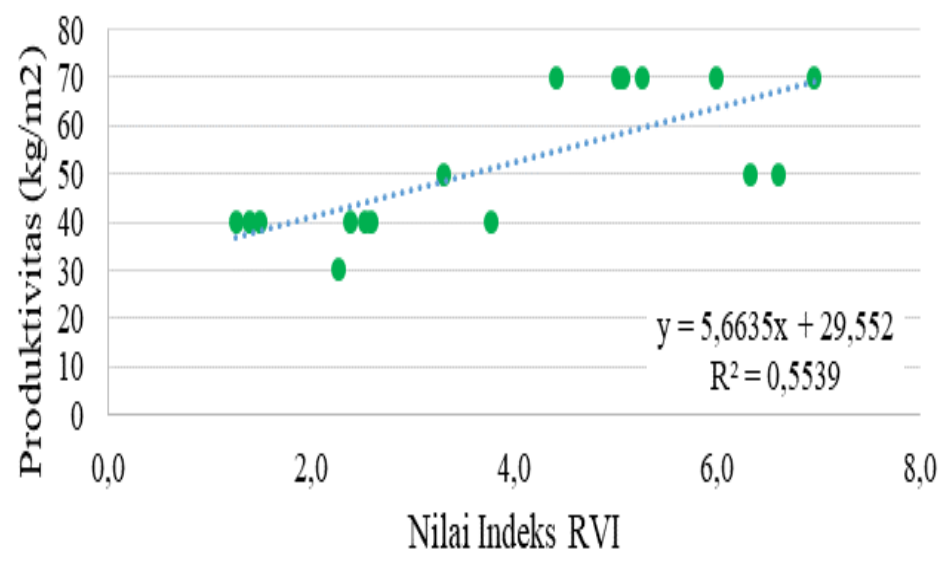

Gambar 3. Grafik Regresi Linier Transformasi RVI

Berdasarkan hasil grafik regresi pada pada Gambar 4 sedangkan luas lahan sawah per Gambar 3, didapat rumus $y=5.67 x+29.5$. kelas produktifitas dapat dilihat pada Tabel 3 . Persamaan tersebut ditransformasikan ulang Produksi padi yang dominan di daerah kajian dengan hasil indeks RVI sebagai nilai $x$. Proses ini berada dalam rentang 47-52 kg/100 m². menghasilkan estimasi produksi padi per piksel $\left(100 \mathrm{~m}^{2}\right)$. Sebaran kelas produksi padi dapat dilihat 


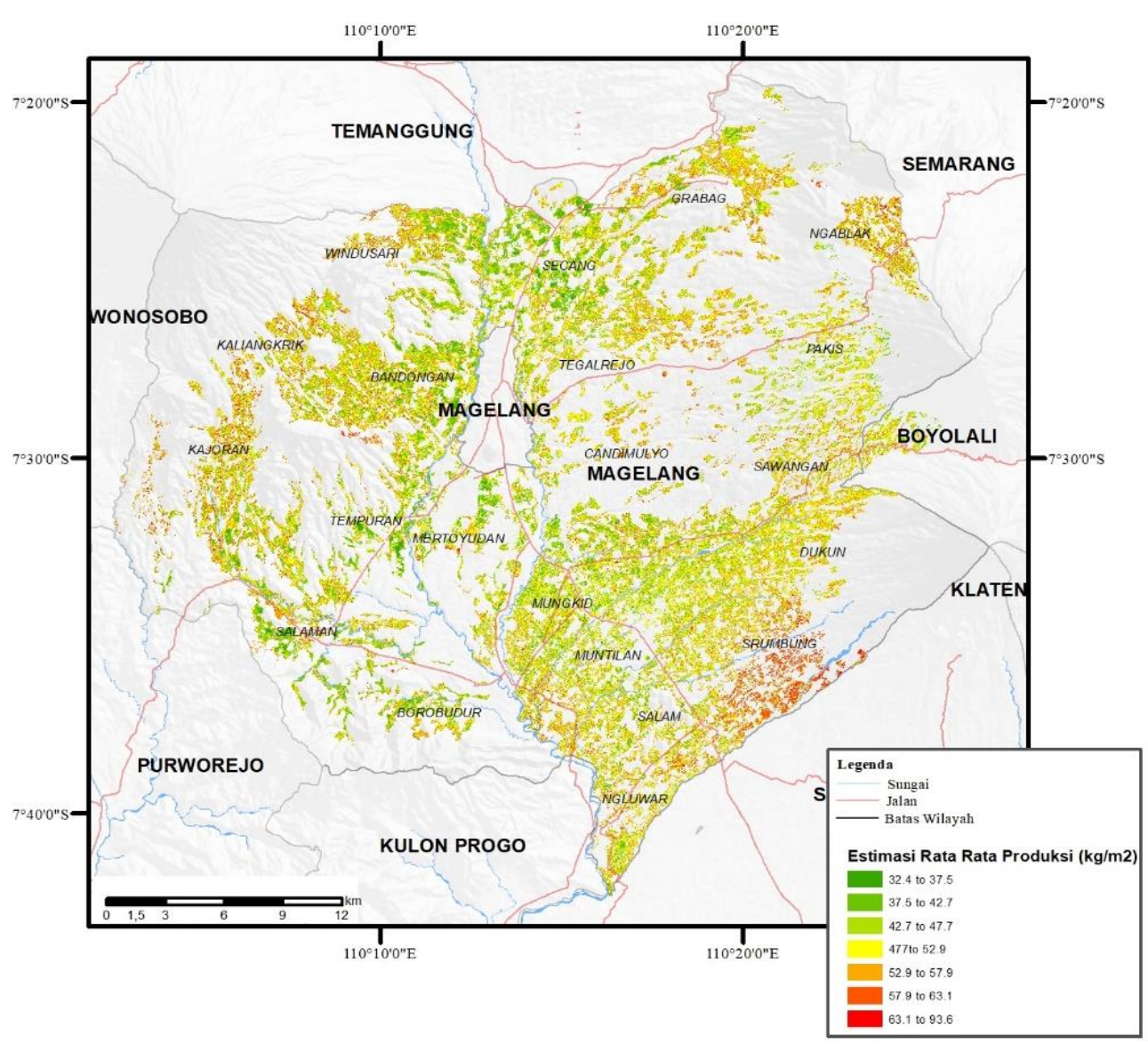

Gambar 4. Sebaran Produktifitas Sawah Rata Rata dalam kg/m2

Tabel 3. Luas Klasifikasi Produksi Padi

\begin{tabular}{ccl}
\hline $\begin{array}{c}\text { Kelas Produksi } \\
\left(\mathrm{kg} / 100 \mathrm{~m}^{2}\right)\end{array}$ & $\begin{array}{c}\text { Luas } \\
(\mathrm{Ha})\end{array}$ & $\begin{array}{c}\text { Persentase } \\
(\%)\end{array}$ \\
\hline $32.48-37.48$ & 239,8 & 0,8 \\
$37.48-42.67$ & $4.827,7$ & 16,9 \\
$42.67-47.67$ & $6.847,7$ & 24,0 \\
$47.67-52.86$ & $7.611,9$ & 26,6 \\
$52.86-57.86$ & $5.983,7$ & 20,9 \\
$57.86-63.05$ & $2.572,7$ & 9,0 \\
$63.05-93.62$ & 482,8 & 1,7 \\
\hline Total & $28.566,3$ & 100 \\
\hline
\end{tabular}

\section{Simpulan}

Berdasarkan penelitian yang dilakukan, dapat disimpulkan bahwa luas lahan sawah hasil klasifikasi menunjukkan nilai 28.566.3 Ha. Dapat disimpulkan juga bahwa nilai indeks vegetasi dan nilai produksi padi di lapangan memiliki korelasi yang cukup singnifikan. Indeks vegetasi terbaik yang dapat digunakan untuk pemodelan adalah RVI. Walaupun RVI memiliki nilai koefisien korelasi yang tinggi, namun hasil klasifikasi produksi rata rata lebih rendah daripada produksi aktual di Kabupaten Magelang. Hasil yang lebih akurat dapat diperoleh dengan menambah sampel lapangan serta menyesuaikan waktu survei dengan perekaman citra.

\section{Ucapan terima kasih}

Penelitian ini tidak dapat terlaksana tanpa kerja sama dari berbagai pihak. Ucapan terimakasih diberikan kepada mahasiswa Program Studi Penginderaan Jauh dan Sistem Infomasi Geografi Sekolah Vokasi UGM yang telah membantu dalam proses verifikasi data lapangan.

\section{Referensi}

Aswin, M. R. dan Murti ,S., 2016. Estimasi Produksi Padi Berbasis Pemrosesan Citra Landsat 8 OLI di Kabupaten Ponorogo. Jurnal Bumi Indonesia 5(4) 
[BPS]Badan Pusat Statistik. (2014). Kajian Indikator Sustainable Development Goals (SDGs). Jakarta: Badan Pusat Statistik

[BPS]Badan Pusat Statistik. (2015). Pedoman Uji Coba Sistem Kerangka Sampel Area (KSA). Jakarta : Badan Pusat Statistik.

Haryono., Psandaran, E., Rachmat, M., Mardianto S., Sumedi., Salim, H., Hendriadi, A. (2014). Reformasi Kebijakan Menuju Transformasi Pembangunan Pertanian. Jakarta: IAARD Press

Jensen, L. L. F. (2000). Principles of Remote Sensing : An Introductory Textbook. Enschede: ITC.

Lillesand, T. M., Kiefer, R. W., \& Chipman, J. W. (2004). Remote Sensing and Image Interpretation, 5th Edition. New York: John Wiley \& Sons.

Murti, S. dan Ratna, N. (2018). Estimasi Produksi Tanaman Kopi Berbasis Pengolahan Citra Landsat 8 di Kabupaten Temanggung Jawa Tengah.

Said, H. S., Subiyanto, S., Yuwono, B. D., (2015). Analisis Produksi Padi dengan Penginderaan Jauh dan Sistem Informasi Geografis di Kota Pekalongan. Jurnal Geodesi Undip.

Sulistyo, B., Gunawan,T., Hartono dan Danoedoro (2011). Pemetaan Faktor C Yang Diturunkan Dari Berbagai Indeks Vegetasi Data Penginderaan Jauh Sebagai Masukan Pemodelan Erosi Di Das Merawu. Jurnal Manusia Dan Lingkungan 18 (1): 68 - 78 